\title{
Article \\ Optimized and Validated DBS/MAE/LC-MS Method for Rapid Determination of Date-Rape Drugs and Cocaine in Human Blood Samples-A New Tool in Forensic Analysis
}

\author{
Paweł Stelmaszczyk (D), Ewa Gacek and Renata Wietecha-Posłuszny *(D) \\ Laboratory for Forensic Chemistry, Department of Analytical Chemistry, Faculty of Chemistry, \\ Jagiellonian University, 2, Gronostajowa St., 30-387 Kraków, Poland; pawel.stelmaszczyk@doctoral.uj.edu.pl (P.S.); \\ ewa.gacek@student.uj.edu.pl (E.G.) \\ * Correspondence: wietecha@chemia.uj.edu.pl or renata.wietecha-posluszny@uj.edu.pl; Tel.: +48-12-686-2008
}

check for updates

Citation: Stelmaszczyk, P.; Gacek, E.; Wietecha-Posłuszny, R. Optimized and Validated DBS/MAE/LC-MS Method for Rapid Determination of Date-Rape Drugs and Cocaine in Human Blood Samples-A New Tool in Forensic Analysis. Separations 2021, 8, 249. https://doi.org/10.3390/ separations 8120249

Academic Editor: Achille Cappiello

Received: 28 November 2021 Accepted: 16 December 2021 Published: 18 December 2021

Publisher's Note: MDPI stays neutral with regard to jurisdictional claims in published maps and institutional affiliations.

Copyright: (c) 2021 by the authors. Licensee MDPI, Basel, Switzerland. This article is an open access article distributed under the terms and conditions of the Creative Commons Attribution (CC BY) license (https:/ / creativecommons.org/licenses/by/ $4.0 /)$.

\begin{abstract}
The aim of this work was to develop a new method for the determination of selected substances from the date-rape drugs group: ketamine, benzodiazepines and cocaine. The method is based on the dried blood spot method which seems to be a suitable tool in the analysis of tested substances. The extraction process based on microwave-assisted extraction was optimized to enable optimal conditions for the isolation of a wide range of analytes from blood samples collected on DBS cards. The extraction with ethyl acetate with a buffer of $\mathrm{pH}=9$ carried out at a temperature of $50{ }^{\circ} \mathrm{C}$ for $15 \mathrm{~min}$ ensured high extraction efficiency of the tested analytes. The optimized method was validated. Limits of detection ( $\mathrm{LOD}=4.38-21.1 \mathrm{ng} / \mathrm{mL}$ ) and quantification (LOQ = 14.6-70.4 ng/mL), interand intra-day precision ( $\mathrm{CV}=1.37-13.4 \%$ and $3.39-14.8 \%$, respectively), recovery $(\mathrm{RE}=93.0-112.4 \%$ ) and matrix effect $(\mathrm{ME}=98.4-101.6 \%)$ were determined. The validation results indicate the possibility of using the proposed method in the analysis of real blood samples collected from victims of sexual assault.
\end{abstract}

Keywords: dried blood spot; date-rape drugs; extraction optimization; LC-MS

\section{Introduction}

Drug-facilitated sexual assault (DFSA) has been a major area of forensic work in recent years. DFSA is the commission of a sexual offence against a victim who is under the influence of a psychoactive substance which in this context is defined as a date-rape drug (DRD) [1]. DRDs usually cause helplessness and loss of consciousness, which in turn leads to the victim's inability to repel the attacker's assault. These substances are generally tasteless, colorless, odorless and dissolve well in water and alcohol [2].

Benzodiazepines, particularly flunitrazepam and diazepam, ketamine, $\gamma$-hydroxybutanoic acid (GHB), cocaine and antidepressants are the most commonly used chemicals in sexual assaults. Many of these drugs may cause depression of the central nervous system (CNS), for example, benzodiazepines, which cause somnolence, sedation and muscle relaxation, and ketamine, which at high doses causes hallucinations and withdrawal from reality [3]. Additionally, some substances are stimulants of the central nervous system, such as the group of amphetamine-type stimulants and cocaine. As an example, cocaine has a strong stimulating effect on the CNS and causes hyperactivity, euphoria, restlessness and increased libido and self-confidence [1]. An important element in confirming a sexual offense committed against a victim under the influence of a psychoactive substance is to collect a urine or blood sample as soon as possible, especially in the case of chemicals with a short half-life. The reason why some drugs are not detected in the body is because they are quickly metabolized. Only a small part of a given substance remains unchanged in the blood and the resulting metabolites are quickly eliminated from the body through urine [4].

Methods used to determine date-rape drugs in biological samples must have high identification capabilities. The more sensitive the method is, the larger the detection 
window and the greater the possibility of a positive outcome [3]. Currently, separations techniques are mainly used, such as high performance liquid chromatography [5-7], gas chromatography $[8,9]$ or capillary electrophoresis [10]. These techniques are usually combined with spectrophotometric or mass detectors to detect substances from the DRD group [11]. For example, in order to determine GHB in hair samples, high performance liquid chromatography-tandem mass (HPLC-MS/MS) preceded by liquid-liquid extraction (LLE) was used [12]. De Paula et al. [13] developed a method using LLE with low temperature partitioning (LLE-LTP) and paper spray mass spectrometry (PS-MS) to identify diazepam and other drugs from the benzodiazepines group.

The dried blood spot (DBS) method is an alternative method of collecting blood samples. The blood sample can be placed on a DBS card by pricking a finger and spotting a drop of blood directly on the filter paper or by using a microcapillary pipette [14]. This method dates back to 1913 and was described by Ivar Christian Bang in his work on the determination of blood glucose levels. Nowadays, DBS sample collection and analysis is used in a wide range of areas, for example, in therapeutic drug monitoring (TDM) [15], infectious disease management, determination of hormones [16] and especially in toxicology. Substances important from the forensic point of view that can be detected by the DBS method are drugs from the benzodiazepine group (diazepam, lorazepam, flunitrazepam, nitrazepam, temazepam, oxazepam), cocaine and its metabolites, ketamine, tetrahydrocannabinol, methadone, opiates, GHB and many others $[17,18]$. Sampling by the DBS technique is relatively easy, micro-invasive and does not require a trained doctor or nurse. Furthermore, the DBS method requires a much smaller sample volume than conventional blood sampling and is less expensive since these samples can be sent to the laboratory by standard mail [19]. The advantages of the DBS method mean that it has a great potential for use in the analysis of substances with a short half-life as it allows for quick and easy collection and protection of biological samples [20]. This is of particular importance for compounds like cocaine and opiates. An additional advantage of the DBS method is the stabilizing effect, which is also important for substances from the DRD group [4]. The use of the DBS method may therefore be applicable in the detection of substances used for sexual assaults, as samples can be taken without waiting for the doctor's arrival. Recently, methods based on DBS and LC-MS combined with traditional liquid-liquid extraction for the determination of abuse drugs are being rapidly developed. The most frequently determined substances for forensic toxicological analyzes by these methods are amphetamine-type stimulants, benzodiazepines, barbiturates, antidepresants, new psychoactive substances (NPS), cocaine and cannabinoids [21-24].

This work describes the development, optimization and validation of a new method for the determination of selected date-rape drugs in blood samples based on the dried blood spot method and microwave assisted extraction (MAE) followed by high performance liquid chromatography with mass spectrometry (LC-MS). We believe that the collection of blood samples on DBS cards could be a useful tool for the quick obtainment of biological samples from rape crime victims, which may increase the chances of detecting short halflife DRDs shortly after the occurrence of the crimes. The MAE extraction which was used in the research presented here could make it possible to increase the extraction efficiency of many substances compared to traditional liquid-liquid extraction.

\section{Materials and Methods}

\subsection{Chemicals and Materials}

Standard solutions of analytes in methanol: flunitrazepam, diazepam, temazepam, nitrazepam, lorazepam, cocaine, norcocaine, cocaethylene, ketamine and their deuterated analogues (flunitrazepam-d3, diazepam-d5, temazepam-d5, nitrazepam-d5) were purchased from Lipomed AG (Arlrshein, Switzerland) at concentrations of $1 \mathrm{mg} / \mathrm{mL}$. All standards were stored in a freezer at $-20{ }^{\circ} \mathrm{C}$.

The other reagents used in the experiment include ethyl acetate, $30 \%$ sodium hydroxide (Merck, Darmstadt, Germany), n-hexane, methanol, acetonitrile, tris(hydroxymethyl) 
aminomethane (TRIS), formic acid, sodium hydrogen phosphate, sodium dihydrogen phosphate, borax (sodium tetraborate, decahydrate), ammonium chloride, ammonium hydroxide (Sigma-Aldrich, St. Louis, MO, USA), 35-38\% hydrochloric acid (POCH, Gliwice, Poland), isoamyl alcohol (Chempur, Piekary Ślaskie, Poland). Ultrapure water (18.2 M $\Omega$ $\mathrm{cm}$, less than $3 \mathrm{ppb}$ TOC) was generated with the Mili-Q Plus system (Merck-Millipore, Darmstadt, Germany) and technical nitrogen with 90-99\% purity (Air Products, Cracow, Poland) was used.

Whatman FTA DMPK C cards and a Harris Unicore puncher $(6 \mathrm{~mm})$ were obtained from Sigma-Aldrich (St. Louis, MO, USA). Falcon vials $(15 \mathrm{~mL})$ were purchased from Nest Biotechnology (Wuxi, China). Eppendorf vials (1.5 and $5 \mathrm{~mL}$ ) were obtained from Eppendorf AG (Hambur, Germany). Vials and inserts $(200 \mu \mathrm{L})$ were produced by VWR (Radnor, PA, USA).

\subsection{Apparatus and Conditions}

For the analyses, the following devices were used. The UltiMate 3000 RS liquid chromatography system (UHPLC; Dionex, Sunnyvale, CA, USA) and Hypersil Gold Phenyl column (50 mm $\times 2.1 \mathrm{~mm}$ ID, particles $1.9 \mu \mathrm{m}$; Thermo Fisher Scientific, Bremen, Germany) were utilized for chromatographic analyses. The liquid chromatograph system was coupled to a MicroTOF-Q II mass spectrometer from Bruker (Bremen, Germany) with an electrospray ionization source (ESI) and a time-of-flight analyzer (TOF). The extraction process was carried out with a MARS 5 microwave-assisted sample preparation system (CEM, Matthews, NC, USA) equipped with Teflon vessels Xpress ${ }^{\circledR}$ PFA. The Allegra X-30R centrifuge was produced by Beckman Coulter Inc. (Indianapolis, IN, USA). The Reax control shaker was acquired from Heidolph (Wood Dale, IL, USA). The nitrogen evaporator was purchased from Lieblisch Labortechnik (Bielefeld, Germany). Automatic pipettes with variable capacity from Hirschmann and Sartorius (Göttingen, Germany) were used.

The settings of the mass detector, gradient program and composition of the mobile phase were chosen based on previous research on psychoactive substances $[25,26]$. The mobile phase consisted of two eluents: eluent $\mathrm{A}$ ( $0.1 \%$ formic acid in ultrapure water) and eluent $\mathrm{B}$ (acetonitrile). The flow rate of the mobile phase was $0.3 \mathrm{~mL} / \mathrm{min}$ and the column temperature was set to $35^{\circ} \mathrm{C}$ during the entire measurement. Eluents A and B were mixed during the analysis according to the following gradient. First, the content of eluent B increased from $15 \%$ to $40 \%(0.0-4.0 \mathrm{~min})$. For the next $3 \mathrm{~min}$, the content of eluent $B$ remained constant at $40 \%(4.0-7.0 \mathrm{~min})$ and then increased to $70 \%$ in $3 \mathrm{~min}(7.0-10.0 \mathrm{~min})$. Next, the content of eluent B was decreased to $15 \%$ in $2.5 \mathrm{~min}$ (10.0-12.5 min) and held for $4.5 \mathrm{~min}(12.5-17.0 \mathrm{~min})$ to stabilize the column prior to the next injection. The injection volume was $5 \mu \mathrm{L}$.

The mass detector parameters were as follows. The detector operated in the positive ionization mode with a capillary voltage of $4.5 \mathrm{kV}$. The nebulizer pressure was 2.5 bar. The dry gas flow and temperature were set to $5.5 \mathrm{~L} / \mathrm{min}$ and $200{ }^{\circ} \mathrm{C}$, respectively. The detector operated in the scanning mode in the range of 50-800 m/z. From the recorded chromatograms, the selected values of $(\mathrm{M}+\mathrm{H})^{+}$ions corresponding to the tested substances were extracted. The extracted $(\mathrm{M}+\mathrm{H})^{+}$values for the analytes and internal standard (IS) and their selected properties are present in Table 1.

\subsection{Blood Sample Collection}

In this study, whole human blood (drug-free) was purchased from a local blood bank (Cracow, Poland). The blood samples were stored in a freezer at $-20^{\circ} \mathrm{C}$.

\subsection{Standard Solution and Calibration Standards}

First, from $1 \mathrm{mg} / \mathrm{mL}$ stock solution, intermediate solutions of flunitrazepam, diazepam, temazepam, nitrazepam, lorazepam, cocaine, norcocaine, cocaethylene, ketamine, flunitrazepam-d3, diazepam-d5, temazepam- $\mathrm{d} 5$ and nitrazepam- $\mathrm{d} 5$ were prepared at a concentration of $10 \mu \mathrm{g} / \mathrm{mL}$ in methanol. Then, by diluting the intermediate solutions, the mix- 
tures of internal standards (flunitrazepam-d3, diazepam-d5, temazepam-d5, nitrazepamd5) at a concentration of $500 \mathrm{ng} / \mathrm{mL}$, analytes (flunitrazepam, diazepam, temazepam, nitrazepam, cocaine, norcocaine, cocaethylene, lorazepam) at a concentration of $500 \mathrm{ng} / \mathrm{mL}$ and ketamine at a concentration of $1000 \mathrm{ng} / \mathrm{mL}$ were prepared.

Table 1. Analytes determined during experiments with the used internal standards (IS) and their selected properties.

\begin{tabular}{|c|c|c|c|c|c|c|c|}
\hline Analyte/IS & Abb. & IS & Formula & pKa $[2,27]$ & $\log P[2,27]$ & $\begin{array}{c}\text { Monitored Ion } \\
(\mathrm{M}+\mathrm{H})^{+}\end{array}$ & $\begin{array}{c}\text { Retention } \\
\text { Time } t_{r} \text { (min) }\end{array}$ \\
\hline Ketamine & KET & FLU-d3 & $\mathrm{C}_{13} \mathrm{H}_{16} \mathrm{ClNO}$ & 7.5 & 3.1 & $238.0993 \pm 0.0050$ & $1.64 \pm 0.03$ \\
\hline Flunitrazepam & FLU & FLU-d3 & $\mathrm{C}_{16} \mathrm{H}_{12} \mathrm{FN}_{3} \mathrm{O}_{3}$ & 1.8 & 2.1 & $314.0935 \pm 0.0050$ & $6.65 \pm 0.02$ \\
\hline Diazepam & DIA & DIA-d5 & $\mathrm{C}_{16} \mathrm{H}_{13} \mathrm{ClN}_{2} \mathrm{O}$ & 3.3 & 2.8 & $285.0789 \pm 0.0050$ & $6.91 \pm 0.01$ \\
\hline Temazepam & TEM & TEM-d5 & $\mathrm{C}_{16} \mathrm{H}_{13} \mathrm{ClN}_{2} \mathrm{O}_{2}$ & 1.6 & 2.2 & $301.0738 \pm 0.0050$ & $6.62 \pm 0.03$ \\
\hline Nitrazepam & NIT & NIT-d5 & $\mathrm{C}_{15} \mathrm{H}_{11} \mathrm{~N}_{3} \mathrm{O}_{3}$ & 3.2 & 2.3 & $282.0873 \pm 0.0050$ & $5.83 \pm 0.02$ \\
\hline Lorazepam & LOR & DIA-d5 & $\mathrm{C}_{15} \mathrm{H}_{10} \mathrm{Cl}_{2} \mathrm{~N}_{2} \mathrm{O}_{2}$ & 1.3 & 2.4 & $321.0192 \pm 0.0050$ & $6.09 \pm 0.01$ \\
\hline Cocaine & $\mathrm{COC}$ & FLU-d3 & $\mathrm{C}_{17} \mathrm{H}_{21} \mathrm{NO}_{4}$ & 8.7 & 2.3 & $304.1543 \pm 0.0050$ & $3.37 \pm 0.04$ \\
\hline Norcocaine & NORC & FLU-d3 & $\mathrm{C}_{16} \mathrm{H}_{19} \mathrm{NO}_{4}$ & 9.6 & 1.7 & $290.1387 \pm 0.0050$ & $3.54 \pm 0.04$ \\
\hline Cocaethylene & COCA & FLU-d3 & $\mathrm{C}_{18} \mathrm{H}_{23} \mathrm{NO}_{4}$ & 8.8 & 2.6 & $318.1700 \pm 0.0050$ & $4.44 \pm 0.02$ \\
\hline Flunitrazepam-d3 (IS) & FLU-d3 & $\mathrm{n} / \mathrm{a}$ & $\mathrm{C}_{16} \mathrm{D}_{3} \mathrm{H}_{9} \mathrm{FN}_{3} \mathrm{O}_{3}$ & $\mathrm{n} / \mathrm{a}$ & $\mathrm{n} / \mathrm{a}$ & $317.1123 \pm 0.0050$ & $6.61 \pm 0.03$ \\
\hline Diazepam-d5 (IS) & DIA-d5 & $\mathrm{n} / \mathrm{a}$ & $\mathrm{C}_{16} \mathrm{D}_{5} \mathrm{H}_{8} \mathrm{ClN}_{2} \mathrm{O}$ & $\mathrm{n} / \mathrm{a}$ & $\mathrm{n} / \mathrm{a}$ & $290.1103 \pm 0.0050$ & $6.85 \pm 0.02$ \\
\hline Temazepam-d5 (IS) & TEM-d5 & $\mathrm{n} / \mathrm{a}$ & $\mathrm{C}_{16} \mathrm{D}_{5} \mathrm{H}_{8} \mathrm{ClN}_{2} \mathrm{O}_{2}$ & $\mathrm{n} / \mathrm{a}$ & $\mathrm{n} / \mathrm{a}$ & $306.1052 \pm 0.0050$ & $6.60 \pm 0.01$ \\
\hline Nitrazepam-d5 (IS) & NIT-d5 & $\mathrm{n} / \mathrm{a}$ & $\mathrm{C}_{15} \mathrm{D}_{5} \mathrm{H}_{6} \mathrm{~N}_{3} \mathrm{O}_{3}$ & $\mathrm{n} / \mathrm{a}$ & $\mathrm{n} / \mathrm{a}$ & $287.1187 \pm 0.0050$ & $5.77 \pm 0.02$ \\
\hline
\end{tabular}

\subsection{Sample Preparation for Optimization of the Extraction Process}

Appropriate amounts of the mixture containing all analytes (at a concentration of $500 \mathrm{ng} / \mathrm{mL}$ ) were pipetted into $1.5 \mathrm{~mL}$ Eppendorf vials and dried under nitrogen gas at $40{ }^{\circ} \mathrm{C}$. Next, appropriate amounts of blood (to a final concentration of all analytes of $250 \mathrm{ng} / \mathrm{mL}$ ), which did not contain the tested analytes, were added to the vials with dried residue and vortexed for $5 \mathrm{~min}$. The samples were applied on the DBS cards as two drops (25 $\mu \mathrm{L}$ each) and then dried at room temperature for at least $3 \mathrm{~h}$.

\subsection{Sample Preparation for Validation of the DBS/MAE/LC-MS Method}

Appropriate amounts of the mixture containing analytes (at a concentration of $500 \mathrm{ng} / \mathrm{mL}$ ) and ketamine (at a concentration of $1000 \mathrm{ng} / \mathrm{mL}$ ) were pipetted into $1.5 \mathrm{~mL}$ Eppendorf vials and dried under nitrogen gas at $40{ }^{\circ} \mathrm{C}$. Next, appropriate amounts of blood (to achieve the desired concentration of analytes in the blood), which did not contain the tested analytes, were added to the vials with dried residues and vortexed for $5 \mathrm{~min}$. The prepared samples were then applied as two drops $(25 \mu \mathrm{L}$ each) on the DBS cards and dried at room temperature for at least $3 \mathrm{~h}$.

\subsection{Extraction Procedure}

Initially, from each sample two $6 \mathrm{~mm}$ diameter discs were cut out from DBS cards using a puncher and inserted into Teflon vessels. Then, $1 \mathrm{~mL}$ of buffer at $\mathrm{pH}=9$ (containing sodium tetraborate and hydrochloric acid) and $3 \mathrm{~mL}$ of ethyl acetate were added to the vessels with DBS discs. The samples were then subjected to microwave-assisted extraction under optimized conditions: $50{ }^{\circ} \mathrm{C}$ for $15 \mathrm{~min}$. After extraction, the contents of the vessels were transferred to $15 \mathrm{~mL}$ plastic tubes and centrifuged $\left(4000 \times \mathrm{g} \mathrm{rpm}, 4^{\circ} \mathrm{C}, 10 \mathrm{~min}\right)$. Next, $2.5 \mathrm{~mL}$ of extractant from plastic tubes was transferred to a $5 \mathrm{~mL}$ Eppendorf vial and dried under nitrogen gas at a temperature of $40{ }^{\circ} \mathrm{C}$. In the next step, $500 \mu \mathrm{L}$ of ethyl acetate was added to residue, vortexed for $10 \mathrm{~s}$ and centrifuged $\left(10,000 \times \mathrm{g} \mathrm{rpm}, 4^{\circ} \mathrm{C}, 10 \mathrm{~min}\right)$. Then, $450 \mu \mathrm{L}$ of the solution was transferred to a $1.5 \mathrm{~mL}$ Eppendorf vial and the mixture was again dried under nitrogen gas at $40{ }^{\circ} \mathrm{C}$. Next, $50 \mu \mathrm{L}$ of eluent A was added to the residue, vortexed for $10 \mathrm{~s}$, and centrifuged $\left(16,000 \times g \mathrm{rpm}, 4^{\circ} \mathrm{C}, 15 \mathrm{~min}\right)$. Finally, $40 \mu \mathrm{L}$ of the sample was placed in a $200 \mu \mathrm{L}$ insert. The prepared samples were analysed using liquid chromatography coupled with a mass spectrometer (LC-MS). The entire sample preparation process takes approximately $3 \mathrm{~h}$. 
The mixture of internal standards was added to the samples at different stages depending on the stage of the research. While optimizing the composition of the extraction mixture and MAE extraction conditions, the internal standards were added to $2.5 \mathrm{~mL}$ of the extractant taken after extraction $(26 \mu \mathrm{L}$ of the mixture of standards at a concentration of $100 \mathrm{ng} / \mathrm{mL}$ was added to each sample). During method validation, the internal standards were added to each of the samples before extraction together with the extractant solution (the concentration of each internal standard in the extractant was $1.5 \mathrm{ng} / \mathrm{mL}$ ).

\subsection{Optimization of Extraction Process}

The first stage in the development of the MAE extraction process was the selection of the appropriate extraction agent (extractant and $\mathrm{pH}$ buffer). Nineteen different extraction mixtures were tested. The extraction process with all tested agents was carried out at the same initial extraction parameters at the temperature of $55^{\circ} \mathrm{C}$ for $10 \mathrm{~min}$. The tested mixtures were evaluated on the basis of the value of the evaluation function described by Equation (1). The evaluation function takes into account the extraction efficiency $\left(E_{n}\right)$ of each analyte, differentiating them into two groups: one for which the $E_{n}$ values of the analytes were above $60 \%$ and the other for which the $E_{n}$ values were below $60 \%$. The standard deviations $\left(S D_{n}\right)$ of the determined extraction efficiency (calculated for the analysis of three independent samples) for each analyte were also taken into account in the proposed evaluation function.

$$
F=\left(k^{2} \cdot \sum_{n=1}^{k} \frac{E_{n}}{S D_{n}}+l \cdot \sum_{n=1}^{l} \frac{E_{n}}{S D_{n}}\right) / 8
$$

The symbols in Equation (1) represent the following values: $F$-value of evaluation function; $E_{n}$ - extraction efficiency of analyte; $S D_{n}$ - standard deviation of extraction efficiency of analyte; $k$-number of analytes for which $E_{n}>60 \%$; l-number of analytes for which $E_{n}<60 \%$.

The extraction efficiency for each analyte was calculated according to the Equation (2):

$$
E_{n}=\frac{I_{A} / I_{I S}}{I_{A 100 \%} / I_{I S 100 \%}}
$$

The symbols in Equation (2) represent the following values: $I_{A} / I_{I S}$-peak areas ratio for the analyte and internal standard of the sample after extraction; $I_{A 100 \%} / I_{I S 100 \%}$ - peak areas ratio for the analyte and internal standard of the sample prepared for the expected extraction efficiency equal to $100 \%$.

For the selected extraction mixture, which was characterized by the best results of the analyte extraction efficiencies, the selected parameters of MAE extraction-temperature and time of extraction-were optimized in the next step of extraction optimization. The parameters of the process were optimized based on the modified simplex method. The same evaluation function (Equation (1)) as in the previous stage was calculated for each performed experiment. First, the initial simplex (experiments A, B and C) was planned. Next, based on the obtained values of the evaluation function, further experiments were performed (experiments D-H). The parameters of the experiment with the highest value of the $\mathrm{F}$ function were found to be the most optimal for the selected extraction mixture.

\subsection{Validation Study}

The validation process was performed according to the guidelines for method validation formulated by the Scientific Working Group for Forensic Toxicology (SWGTOX) [28] and took into account the general recommendations given by the International Association for Therapeutic Drug Monitoring and Clinical Toxicology for the development and validation of dried blood spot methods [29]. The calculation strategy of Majda et al. [25] was used to reduce the influence of volume and hematocrit effects on the results of the analyses. The validation process was carried out using blood free of the tested analytes. All samples 
were spiked with the examined drugs. The preparation procedure for spiked samples is presented in Section 2.6.

The linearity of the method was determined in the working range of $25-300 \mathrm{ng} / \mathrm{mL}$ for each analyte, except ketamine, for which linearity was tested in the working range of $125-400 \mathrm{ng} / \mathrm{mL}$. Calibration samples were prepared at concentrations of 25, 50, 100, 150, 200, 250 and $300 \mathrm{ng} / \mathrm{mL}$ (125, 150, 200, 250, 300, 350 and $400 \mathrm{ng} / \mathrm{mL}$ for ketamine). Calibration curves were calculated based on the internal standard method and the linear regression model. The peak area ratio of the analyte and internal standard was taken as the recorded signal for each calibration concentration.

The limits of detection $(L O D)$ and quantification $(L O Q)$ for each analyte were estimated based on the value of standard deviation of the calculated concentration for the lowest calibration samples $\left(S D_{l}\right)$ and the slope of the calibration curve according to Equations (3) and (4).

$$
\begin{aligned}
& L O D=\frac{3.3 \cdot S D_{I}}{\text { Slope }} \\
& L O Q=\frac{10 \cdot S D_{I}}{\text { Slope }}
\end{aligned}
$$

The precision $(C V)$ and recovery $(R E)$ of the method were determined for analytes at the concentration of 50, 150 and $300 \mathrm{ng} / \mathrm{mL}$ in blood samples. These parameters for ketamine were calculated at the concentration of 150,200 and $400 \mathrm{ng} / \mathrm{mL}$ in blood samples, based on the different range of examined linearity for this analyte. The intra-day precision was evaluated by the analysis of three samples for each tested concentration level and each sample analysis was repeated three times $(n=9)$. The inter-day precision was evaluated by repeating the same analysis on three consecutive days $(n=27)$. The coefficients of variation $(\mathrm{CV} \%)$ for intra- and inter-day precision were calculated based on the standard deviation (SD) and the average determined concentration $\left(C_{a v}\right)$ for the analysed samples, according to Equation (5). The recovery of the method was determined based on the results obtained for the four samples for each concentration level based on the average concentration determined for the analysed samples $\left(C_{a v}\right)$ and the nominal concentration in the sample $\left(C_{n}\right)$ according to Equation (6).

$$
\begin{gathered}
C V \%=\frac{S D}{C_{a v}} \cdot 100 \% \\
R E=\frac{C_{a v}}{C_{n}} \cdot 100 \%
\end{gathered}
$$

The matrix effect (ME) was tested based on the analysis of six blank samples collected from six different volunteers. The blood samples were spiked with the tested analytes at a concentration of $300 \mathrm{ng} / \mathrm{mL}$ ( $400 \mathrm{ng} / \mathrm{mL}$ for ketamine) and then applied on DBS cards. The results obtained from the analyses of the six samples were compared to results of the analyses of samples which did not contain blood matrix. All samples prepared for the matrix effect investigation did not contain internal standards; only the signals for the tested substances were compared. The samples were prepared according to the protocol suggested by Majda et al. [25], which is useful for blood samples of unknown hematocrit.

\section{Results and Discussion}

\subsection{Optimization of the MAE Extraction}

The first step of extraction optimization was to find the most optimal extraction mixture to extract all tested analytes with the highest values of extraction efficiency yet also with acceptable repeatability of the extraction process. Nineteen different extraction mixtures (I-XIX) were tested during the performed experiments. The tested extractants included ethyl acetate, methanol, acetonitrile, hexane, isoamyl alcohol and their mixtures. Some of the tested mixtures also contained a buffer with a known $\mathrm{pH}$ value in order to 
increase the affinity of the analytes for the organic phase. The composition of individual mixtures and the calculated values of the evaluation function $F$ are presented in Table 2.

Table 2. Composition of extraction mixtures with values of the evaluation function $\mathrm{F}$.

\begin{tabular}{|c|c|c|c|c|}
\hline \multirow{2}{*}{ Mixture No. } & \multicolumn{3}{|c|}{ Extraction Mixture } & \multirow{2}{*}{$\mathbf{F}$} \\
\hline & Extractant & Extraction Medium & $\mathrm{pH}$ & \\
\hline I & Ethyl acetate & $0.6 \mathrm{M} \mathrm{NaOH}$ & 13.5 & 19 \\
\hline II & Hexane: isoamyl alcohol (99:1) & $0.6 \mathrm{M} \mathrm{NaOH}$ & 13.5 & 1 \\
\hline III & $\begin{array}{c}\text { Ethyl acetate: hexane: isoamyl } \\
\text { Alcohol (49.5:49.5:1) }\end{array}$ & $0.6 \mathrm{M} \mathrm{NaOH}$ & 13.5 & 8 \\
\hline IV & Methanol & -1 & -1 & 374 \\
\hline $\mathrm{V}$ & Acetonitrile & -1 & -1 & 49 \\
\hline VI & Ethyl acetate & $\mathrm{C}_{4} \mathrm{H}_{11} \mathrm{NO}_{3}+\mathrm{NaH}_{2} \mathrm{PO}_{4}$ & 2 & 6 \\
\hline VII & Ethyl acetate & $\mathrm{Na}_{2} \mathrm{HPO}_{4}+\mathrm{NaH}_{2} \mathrm{PO}_{4}$ & 7 & 51 \\
\hline VIII & Ethyl acetate & $\mathrm{H}_{2} \mathrm{O}$ & 7 & 38 \\
\hline IX & Ethyl acetate & $\mathrm{Na}_{2} \mathrm{HPO}_{4}+\mathrm{NaH}_{2} \mathrm{PO}_{4}$ & 8 & 211 \\
\hline$x$ & Ethyl acetate & $\mathrm{Na}_{2} \mathrm{~B}_{4} \mathrm{O}_{7}+\mathrm{HCl}$ & 9 & 600 \\
\hline XI & Ethyl acetate & $\mathrm{NH}_{3} \cdot \mathrm{H}_{2} \mathrm{O}+\mathrm{NH}_{4} \mathrm{Cl}$ & 9 & 43 \\
\hline XII & Ethyl acetate & $\mathrm{NH}_{3} \cdot \mathrm{H}_{2} \mathrm{O}+\mathrm{NH}_{4} \mathrm{Cl}$ & 10 & 374 \\
\hline XIII & Ethyl acetate & $\mathrm{NH}_{3} \cdot \mathrm{H}_{2} \mathrm{O}+\mathrm{NH}_{4} \mathrm{Cl}$ & 11 & 19 \\
\hline XIV & Ethyl acetate: methanol (3:1) & -1 & -1 & 21 \\
\hline XV & Ethyl acetate: methanol (1:1) & -1 & -1 & 78 \\
\hline XVI & Ethyl acetate: methanol (1:3) & -1 & -1 & 10 \\
\hline XVII & Acetonitrile: methanol (3:1) & -1 & -1 & 108 \\
\hline XVIII & Acetonitrile: methanol (1:1) & -1 & -1 & 70 \\
\hline XIX & Acetonitrile: methanol (1:3) & -1 & -1 & 54 \\
\hline
\end{tabular}

${ }^{1}$ Extration mixture did not contain extraction medium.

Based on the results for the mixtures I-V, the buffer of $\mathrm{pH}=13.5$ was found to have no effect on the transfer of analytes to the organic phase. From these tested mixtures good results were obtained for methanol; however, this extractant also extracts other matrix components, making the further sample preparation procedure more difficult. The extracts obtained with ethyl acetate were the cleanest, therefore, in the next step mixtures containing this extractant with different $\mathrm{pH}$ buffers were tested. Additionally, mixtures of ethyl acetate, methanol and acetonitrile in various ratios were investigated.

In further tested mixtures containing ethyl acetate with different $\mathrm{pH}$ buffers (VI$\mathrm{XIII}$ ), the best results were obtained for the systems with buffers of $\mathrm{pH}=9$ (mixture $\mathrm{X}$ ) and $\mathrm{pH}=10$ (mixture XII). Both extraction agents were characterized by high repeatability of the extraction process; however, ethyl acetate with a buffer of $\mathrm{pH}=9$ allowed an increase in the extraction efficiency of the tested analytes. The mixtures of organic solvents without a buffer (XIV-XIX) did not ensure a reproducible extraction process. The lower reproducibility for this group of agents could be caused by the fact that the sample matrix compounds were also extracted with these mixtures, which made further sample preparation steps more difficult, e.g., due to the evaporation of solvents after extraction.

At this stage of optimization of the MAE extraction process, the mixture of ethyl acetate and a buffer with a $\mathrm{pH}$ equal to 9 , which consisted of sodium tetraborate and hydrochloric acid, was considered as the best extraction agent for the tested analytes.

In the next step of the optimization process the MAE extraction conditions were optimized for the extraction mixture selected in previous experiments. This stage was performed using a modified simplex methodology. First, the parameters of the initial simplex were defined (experiments A-C). Based on the results for these conditions, the parameters of the next experiment were determined using appropriate mathematical operations. The experimental design was continued for the next five experiments $(\mathrm{D}-\mathrm{H})$. The values of the parameters of subsequent experiments and their results are presented in Table 3. 
Table 3. Simplex optimization plan and results of experiments A-H.

\begin{tabular}{ccccc}
\hline Experiment & Time (min) & Temperature $\left({ }^{\circ} \mathbf{C}\right)$ & Operation & F \\
\hline A & 10 & 55 & None, initial simplex & 263 \\
B & 10 & 65 & None, initial simplex & 137 \\
C & 15 & 60 & None, initial simplex & 154 \\
D & 15 & 50 & Reflection of B & 833 \\
E & 18 & 40 & Expansion of D & 283 \\
F & 13 & 35 & Reflection of C & 243 \\
G & 13 & 50 & Contraction towards D & 455 \\
H & 10 & 60 & Reflection of E & 166 \\
\hline
\end{tabular}

Based on the results obtained for experiments A-H, the MAE extraction carried out at $50{ }^{\circ} \mathrm{C}$ for $15 \mathrm{~min}$ (experiment $\mathrm{D}$ ) seemed to involve the best conditions for the extraction of the tested drugs using ethyl acetate with a buffer of $\mathrm{pH}=9$ as the extraction agent. The result of experiment $G$, the conditions of which are close to the found optimum, also showed good efficiency. This fact may indicate that the application of the experimental design made it possible to find the actual optimum conditions for the tested extraction agents. Figure 1 presents a bar chart showing the extraction efficiency values obtained for the tested analytes under optimized extraction conditions.

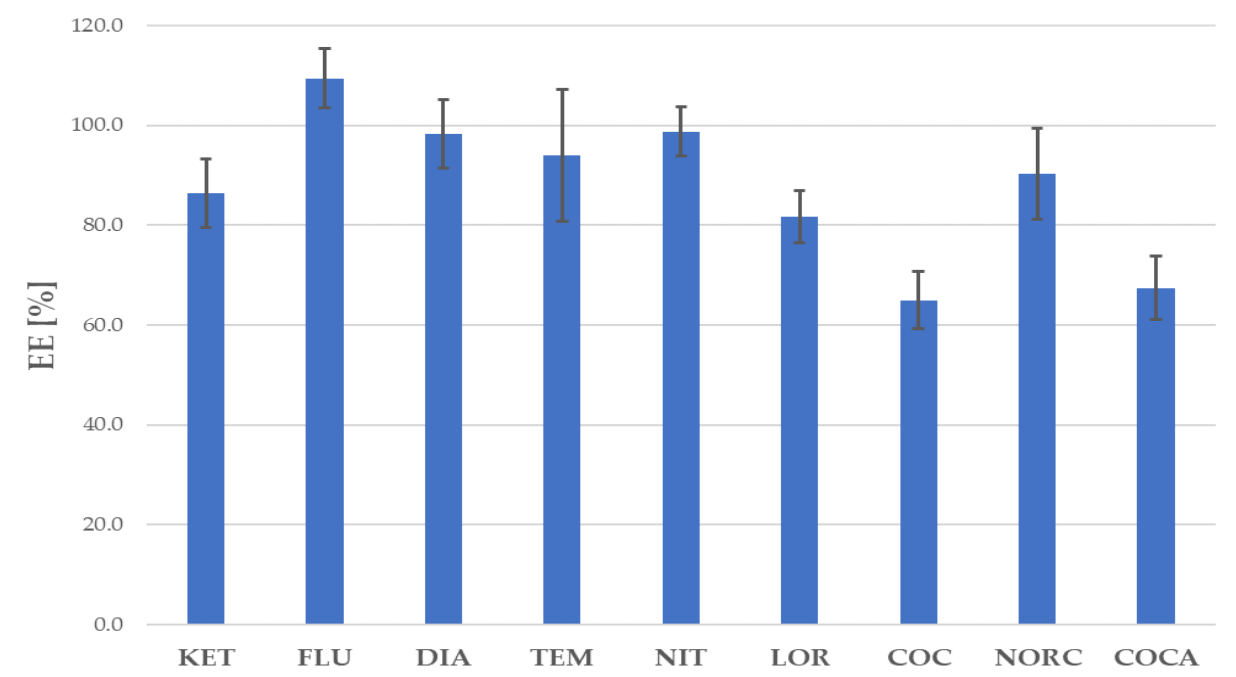

Figure 1. Extraction efficiency (EE) for the tested analytes under optimized extraction conditions.

\subsection{Validation of the Method}

Validation parameters, such as linearity, limit of detection, limit of quantification, intra- and inter-day precision, recovery and absolute matrix effect, were determined for all analytes. The values of validation parameters are present in Table 4.

The developed method is characterized by good linearity in the working range of $125-400 \mathrm{ng} / \mathrm{mL}$ for ketamine and $25-300 \mathrm{ng} / \mathrm{mL}$ for other analytes. The values of Rsquared $\left(R^{2}\right)$ for the calibration curves in these ranges were above 0.98 for most of the tested drugs. Only for ketamine $\left(R^{2}=0.9770\right)$ and lorazepam $\left(R^{2}=0.9696\right)$ were the values of this parameter lower. However, all determined $\mathrm{R}^{2}$ values prove the linear dependence of the signal in the tested concentration range for all analytes. Figure 2 presents the chromatogram of the spiked blood sample at the highest concentration of the working range. 
Table 4. Validation parameters of the optimized DBS/MAE/LC-MS method.

\begin{tabular}{|c|c|c|c|c|c|c|}
\hline \multirow{2}{*}{\multicolumn{2}{|c|}{ Parameter }} & \multicolumn{5}{|c|}{ Analyte } \\
\hline & & FLU & DIA & TEM & NIT & LOR \\
\hline \multicolumn{2}{|c|}{$\mathrm{R}^{2}$} & 0.9960 & 0.9879 & 0.9925 & 0.9942 & 0.9696 \\
\hline \multicolumn{2}{|c|}{ Slope } & 0.0010 & 0.0043 & 0.0043 & 0.0045 & 0.0048 \\
\hline \multicolumn{2}{|c|}{ Intercept } & -0.0151 & -0.0346 & -0.0138 & -0.0343 & 0.0083 \\
\hline \multicolumn{2}{|c|}{$\mathrm{LOD}(\mathrm{ng} / \mathrm{mL})$} & 7.08 & 4.92 & 7.08 & 4.38 & 6.19 \\
\hline \multicolumn{2}{|c|}{ LOQ (ng/mL) } & 23.3 & 16.4 & 23.6 & 14.6 & 20.6 \\
\hline \multicolumn{7}{|c|}{ Precision, CV (\%): } \\
\hline \multirow{3}{*}{ Intra-day $(\mathrm{n}=9)$} & Low concentration ${ }^{1}$ & 6.23 & 4.84 & 6.56 & 6.18 & 12.6 \\
\hline & Medium concentration ${ }^{1}$ & 9.27 & 5.27 & 8.81 & 3.41 & 9.25 \\
\hline & High concentration $^{1}$ & 3.48 & 5.90 & 1.37 & 7.65 & 4.21 \\
\hline \multirow{3}{*}{ Inter-day $(\mathrm{n}=27)$} & Low concentration $^{1}$ & 8.91 & 9.93 & 8.56 & 11.8 & 14.8 \\
\hline & Medium concentration $^{1}$ & 8.65 & 8.94 & 7.48 & 8.96 & 14.1 \\
\hline & High concentration $^{1}$ & 5.34 & 7.81 & 7.36 & 8.43 & 10.1 \\
\hline \multicolumn{7}{|c|}{ Recovery, RE (\%) $(\mathrm{n}=4)$ : } \\
\hline & Low concentration ${ }^{1}$ & 95.1 & 104.1 & 96.4 & 111.2 & 100.5 \\
\hline & Medium concentration $^{1}$ & 107.9 & 109.8 & 101.5 & 97.5 & 101.2 \\
\hline & High concentration $^{1}$ & 101.4 & 96.9 & 97.5 & 98.6 & 101.5 \\
\hline \multicolumn{2}{|c|}{ Matrix effect, ME $(\%)(n=6)$} & $99.5 \pm 2.5$ & $101.6 \pm 1.4$ & $98.7 \pm 2.4$ & $98.4 \pm 2.0$ & $99.2 \pm 1.9$ \\
\hline \multirow{2}{*}{\multicolumn{2}{|c|}{ Parameter }} & \multicolumn{5}{|c|}{ Analyte } \\
\hline & & KET & $\mathrm{COC}$ & NORC & \multicolumn{2}{|c|}{ COCA } \\
\hline \multicolumn{2}{|c|}{$\mathrm{R}^{2}$} & 0.9770 & 0.9856 & 0.9865 & \multicolumn{2}{|c|}{0.9927} \\
\hline \multicolumn{2}{|c|}{ Slope } & 0.009 & 0.0009 & 0.0008 & \multicolumn{2}{|c|}{0.0010} \\
\hline \multicolumn{2}{|c|}{ Intercept } & -0.0153 & -0.0118 & -0.0181 & \multicolumn{2}{|c|}{-0.0212} \\
\hline \multicolumn{2}{|c|}{ LOD (ng/mL) } & 21.1 & 6.25 & 5.07 & \multicolumn{2}{|c|}{6.09} \\
\hline \multicolumn{2}{|c|}{ LOQ (ng/mL) } & 70.4 & 20.8 & 16.9 & \multicolumn{2}{|c|}{20.3} \\
\hline \multicolumn{7}{|c|}{ Precision, CV (\%): } \\
\hline \multirow{3}{*}{ Intra-day $(\mathrm{n}=9)$} & Low concentration $^{1}$ & 6.39 & 6.10 & 6.29 & & \\
\hline & Medium concentration ${ }^{1}$ & 5.84 & 5.69 & 5.32 & & \\
\hline & High concentration $^{1}$ & 13.4 & 3.32 & 3.59 & & \\
\hline & Low concentration ${ }^{1}$ & 10.2 & 7.74 & 9.79 & & \\
\hline Inter-day $(\mathrm{n}=27)$ & Medium concentration $^{1}$ & 7.75 & 8.15 & 8.97 & & \\
\hline & High concentration ${ }^{1}$ & 7.26 & 3.39 & 7.65 & & \\
\hline Recover & $E(\%)(n=4):$ & & & & & \\
\hline & Low concentration ${ }^{1}$ & 102.6 & 112.4 & 94.2 & & \\
\hline & Medium concentration ${ }^{1}$ & 100.0 & 99.3 & 93.0 & & \\
\hline & High concentration $^{1}$ & 95.4 & 104.5 & 98.7 & & \\
\hline Matrix eff & $\operatorname{ME}(\%)(n=6)$ & $99.7 \pm 2.1$ & $101.2 \pm 2.2$ & $100.1 \pm 3.6$ & 98.7 & 0.9 \\
\hline
\end{tabular}

${ }^{1}$ Low concentration- $50 \mathrm{ng} / \mathrm{mL}$ (150 ng/mL for KET); medium concentration—150 ng/mL (250 ng/mL for KET); high concentration$300 \mathrm{ng} / \mathrm{mL}$ (400 ng/mL for KET). 


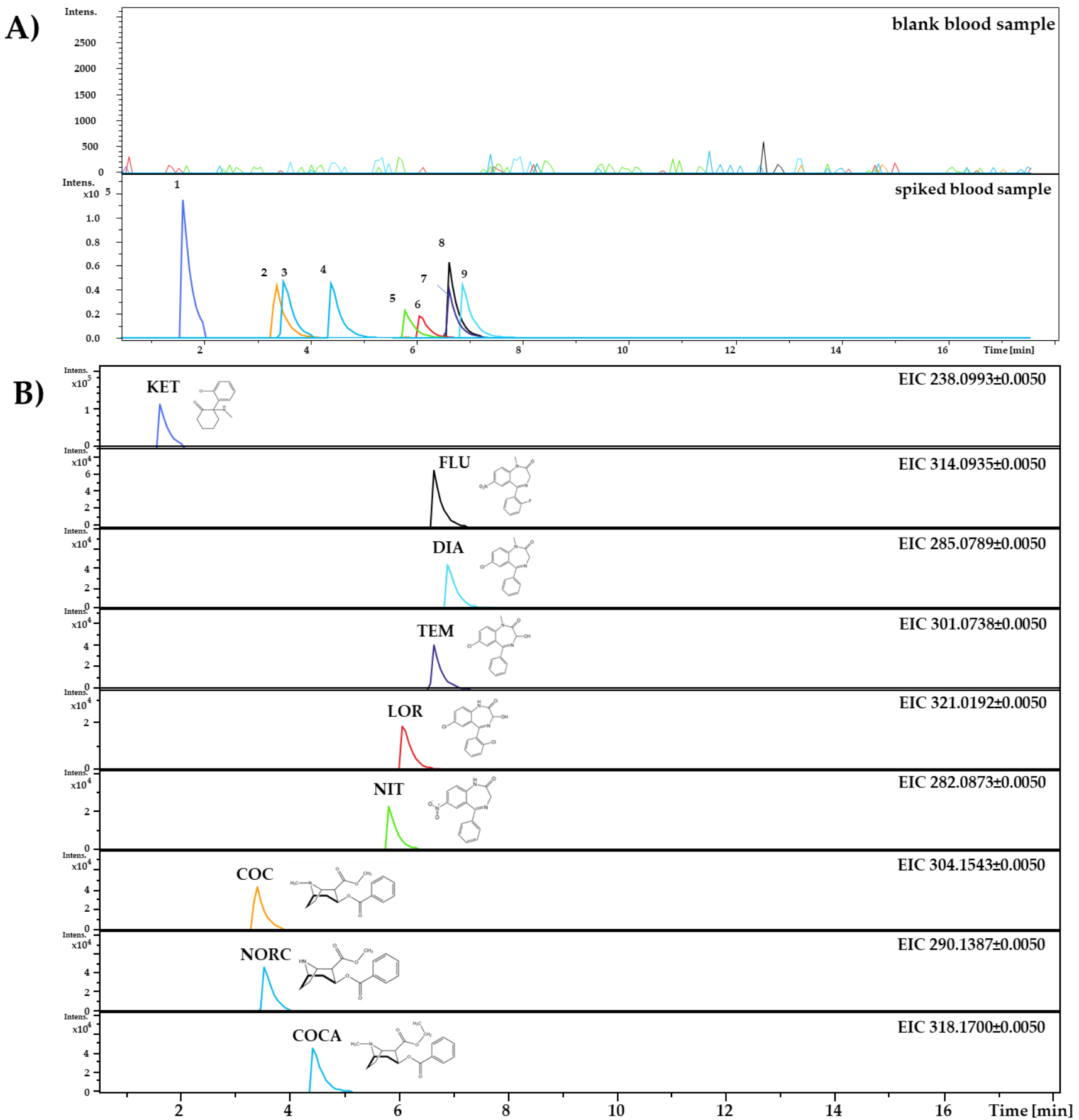

Figure 2. Chromatogram obtained for the spiked blood sample for analytes at a concentration of $300 \mathrm{ng} / \mathrm{mL}$ (for KET$400 \mathrm{ng} / \mathrm{mL}$ ). (A) Chromatograms for the blank and spiked blood samples (1-KET, 2-COC, 3-NORC, 4-COCA, 5-NIT, 6-LOR, 7-TEM, 8-FLU, 9-DIA). (B) Extracted chromatograms for all analytes.

The estimated values of limits of detection indicated that the developed method enables the detection of tested analytes at the concentration of even a few $\mathrm{ng} / \mathrm{mL}$. The values of limits of quantification were almost close to the lowest calibration concentration. Higher LOD and LOQ values were obtained for ketamine. Due to the fact that during the validation process there were problems with the detection of ketamine at the lower concentrations of 25 and $50 \mathrm{ng} / \mathrm{mL}$, it was decided to investigate the linearity for ketamine in a higher range (125-400 $\mathrm{ng} / \mathrm{mL}$ ). The estimated LOD and LOQ for ketamine during the validation process confirmed that the developed method could not detect the substance 
at lower concentrations. The obtained values of LOD and LOQ for other analytes were satisfactory.

The intra-day and inter-day precision of determinations at the three investigated concentration levels were within the range of $1.37-13.4 \%$ and $3.39-14.8 \%$, respectively. The values of precision for the tested analytes did not exceed the acceptance limit of $15 \%$ (according to the SWGTOX guideline [28]). The accuracy of the method at the tested concentration levels is close to $100 \%$. The optimized method could be considered precise and accurate.

The matrix effect for all analytes was in the range of 98.4-101.6\%. The obtained values close to $100 \%$ indicate the lack of influence of the biological samples' matrixes on the ionization process of analytes. The matrix effect values indicate that the developed extraction process enables the isolation of the tested analytes from the blood matrix without sample components that may interfere with the analyzed substances.

According to the results obtained for the validation process, the developed method seems to be suitable for the quantitative analysis of the tested substances belonging to the group of date-rape drugs-ketamine, selected benzodiazepines, cocaine and its metabolites-in blood samples. In future studies, more specific validation parameters could be determined, such as dilution effects and the carryover and stability of analytes in samples collected on DBS cards.

\section{Conclusions}

The developed and validated DBS/MAE/LC-MS method presented in this work could be used for the obtainment of blood samples and their qualitative and quantitative analysis. The conditions of MAE extraction were optimized during this study, with the optimal parameters chosen based on the experimental design (modified simplex method). Optimized MAE extraction enables the isolation of analytes from whole blood samples with high extraction efficiencies.

A significant advantage of this method is that it required a small amount of blood as a sample (50 $\mu \mathrm{L}$ of whole blood). This method seems to be very sensitive, allowing the detection of tested substances at concentrations of even a few $\mathrm{ng} / \mathrm{mL}$. The obtained validation parameters are satisfactory according to the SWGTOX criteria [28]. The results of validation indicate the possibility of using this method to analyze blood samples containing selected date-rape drugs.

The developed DBS/MAE/LC-MS method is a good alternative for routine methods based on taking blood samples in the most common way, i.e., directly from the veins. Future studies should focus on the analysis of real case samples collected from victims of drug-facilitated sexual assaults and those who are intoxicated with the tested substances.

Author Contributions: Conceptualization, P.S. and R.W.-P.; methodology, P.S. and R.W.-P.; validation, P.S. and E.G.; formal analysis, P.S. and E.G.; investigation, P.S., E.G. and R.W.-P.; resources, P.S., E.G. and R.W.-P.; writing — original draft preparation, P.S. and E.G.; writing-review and editing, P.S., E.G. and R.W.-P.; visualization, P.S. and E.G.; supervision, R.W.-P.; project administration, R.W.-P.; funding acquisition, R.W.-P. All authors have read and agreed to the published version of the manuscript.

Funding: This research was funded by the National Science Centre (Poland), Preludium Bis 1, grant number 2019/35/O/ST4/00978.

Institutional Review Board Statement: Not applicable.

Informed Consent Statement: Not applicable.

Data Availability Statement: Data sharing not applicable.

Acknowledgments: The authors gratefully acknowledge the financial support of the Ministry of Science and Higher Education, National Science Centre, Poland (R. Wietecha-Posłuszny, Preludium Bis 1, no. 2019/35/O/ST4/00978).

Conflicts of Interest: The authors declare no conflict of interest. 


\section{References}

1. Bertol, E.; Di Milia, M.G.; Fioravanti, A.; Mari, F.; Palumbo, D.; Pascali, J.P.; Vaiano, F. Proactive drugs in DFSA cases: Toxicological findings in an eight-years study. Forensic Sci. Int. 2018, 291, 207-215. [CrossRef]

2. Moffat, A.C.; Osselton, M.D.; Clarke, D.W. Analysis of Drugs and Poisons. Ren. Dis. Illus. Guid. 2011, 149-150, 73-76. [CrossRef]

3. de Costa, Y.R.S.; Lavorato, S.N.; de Baldin, J.J.C.M.C. Violence against women and drug-facilitated sexual assault (DFSA): A review of the main drugs. J. Forensic Leg. Med. 2020, 74, 102020. [CrossRef] [PubMed]

4. Chan, W.-S.; Wong, G.F.; Hung, C.-W.; Wong, Y.-N.; Fung, K.-M.; Lee, W.-K.; Dao, K.-L.; Leung, C.-W.; Lo, K.-M.; Lee, W.-M.; et al. Interpol review of toxicology 2016-2019. Forensic Sci. Int. Synerg. 2020, 2, 563-607. [CrossRef] [PubMed]

5. Adamowicz, P.; Tokarczyk, B. Simple and rapid screening procedure for 143 new psychoactive substances by liquid chromatography-tandem mass spectrometry. Drug Test. Anal. 2016, 8, 652-667. [CrossRef] [PubMed]

6. Vaiano, F.; Busardò, F.P.; Palumbo, D.; Kyriakou, C.; Fioravanti, A.; Catalani, V.; Mari, F.; Bertol, E. A novel screening method for 64 new psychoactive substances and 5 amphetamines in blood by LC-MS/MS and application to real cases. J. Pharm. Biomed. Anal. 2016, 129, 441-449. [CrossRef]

7. Fisichella, M.; Odoardi, S.; Strano-Rossi, S. High-throughput dispersive liquid/liquid microextraction (DLLME) method for the rapid determination of drugs of abuse, benzodiazepines and other psychotropic medications in blood samples by liquid chromatography-tandem mass spectrometry (LC-MS/MS) and app. Microchem. J. 2015, 123, 33-41. [CrossRef]

8. Mercieca, G.; Odoardi, S.; Cassar, M.; Strano Rossi, S. Rapid and simple procedure for the determination of cathinones, amphetamine-like stimulants and other new psychoactive substances in blood and urine by GC-MS. J. Pharm. Biomed. Anal. 2018, 149, 494-501. [CrossRef]

9. Moreno, I.; Barroso, M.; Martinho, A.; Cruz, A.; Gallardo, E. Determination of ketamine and its major metabolite, norketamine, in urine and plasma samples using microextraction by packed sorbent and gas chromatography-tandem mass spectrometry. $J$. Chromatogr. B Anal. Technol. Biomed. Life Sci. 2015, 1004, 67-78. [CrossRef]

10. Swiadro, M.; Stelmaszczyk, P.; Lenart, I.; Wietecha-Posłuszny, R. The double face of ketamine-the possibility of its identification in blood and beverages. Molecules 2021, 26, 813. [CrossRef] [PubMed]

11. Soni, S.; Jain, U.; Chauhan, N. A systematic review on sensing techniques for drug- facilitated sexual assaults (DFSA) monitoring. Chinese J. Anal. Chem. 2021, 49, 83-92. [CrossRef]

12. Bertol, E.; Mari, F.; Vaiano, F.; Romano, G.; Zaami, S.; Baglì, G.; Busardò, F.P. Determination of GHB in human hair by HPLCMS/MS: Development and validation of a method and application to a study group and three possible single exposure cases. Drug Test. Anal. 2015, 7, 376-384. [CrossRef]

13. de Paula, C.; Jurisch, M.; Piccin, E.; Augusti, R. Recognizing drug-facilitated crimes: Detection and quantification of benzodiazepines in beverages using fast liquid-liquid extraction with low temperature partitioning and paper spray mass spectrometry. Drug Test. Anal. 2018, 10, 1348-1357. [CrossRef] [PubMed]

14. Martial, L.C.; Aarnoutse, R.E.; Mulder, M.; Schellekens, A.; Brüggemann, R.J.M.; Burger, D.M.; Schene, A.H.; Batalla, A. Dried Blood Spot sampling in psychiatry: Perspectives for improving therapeutic drug monitoring. Eur. Neuropsychopharmacol. 2017, 27, 205-216. [CrossRef]

15. Świądro, M.; Stelmaszczyk, P.; Wietecha-Posłuszny, R.; Dudek, D. Development of a new method for drug detection based on a combination of the dried blood spot method and capillary electrophoresis. J. Chromatogr. B Anal. Technol. Biomed. Life Sci. 2020, 1157, 122339. [CrossRef] [PubMed]

16. Fischer, S.; Obrist, R.; Ehlert, U. How and when to use dried blood spots in psychoneuroendocrinological research. Psychoneuroendocrinology 2019, 108, 190-196. [CrossRef] [PubMed]

17. Stove, C.P.; Ingels, A.S.M.E.; De Kesel, P.M.M.; Lambert, W.E. Dried blood spots in toxicology: From the cradle to the grave? Crit. Rev. Toxicol. 2012, 42, 230-243. [CrossRef] [PubMed]

18. Kyriakou, C.; Marchei, E.; Scaravelli, G.; García-Algar, O.; Supervía, A.; Graziano, S. Identification and quantification of psychoactive drugs in whole blood using dried blood spot (DBS) by ultra-performance liquid chromatography tandem mass spectrometry. J. Pharm. Biomed. Anal. 2016, 128, 53-60. [CrossRef] [PubMed]

19. Luginbühl, M.; Gaugler, S. The application of fully automated dried blood spot analysis for liquid chromatography-tandem mass spectrometry using the CAMAG DBS-MS 500 autosampler. Clin. Biochem. 2020, 82, 33-39. [CrossRef] [PubMed]

20. Tré-Hardy, M.; Capron, A.; Antunes, M.V.; Linden, R.; Wallemacq, P. Fast method for simultaneous quantification of tamoxifen and metabolites in dried blood spots using an entry level LC-MS/MS system. Clin. Biochem. 2016, 49, 1295-1298. [CrossRef]

21. Chepyala, D.; Tsai, I.L.; Liao, H.W.; Chen, G.Y.; Chao, H.C.; Kuo, C.H. Sensitive screening of abused drugs in dried blood samples using ultra-high-performance liquid chromatography-ion booster-quadrupole time-of-flight mass spectrometry. J. Chromatogr. A 2017, 1491, 57-66. [CrossRef] [PubMed]

22. Joye, T.; Sidibé, J.; Déglon, J.; Karmime, A.; Sporkert, F.; Widmer, C.; Favrat, B.; Lescuyer, P.; Augsburger, M.; Thomas, A. Liquid chromatography-high resolution mass spectrometry for broad-spectrum drug screening of dried blood spot as microsampling procedure. Anal. Chim. Acta 2019, 1063, 110-116. [CrossRef]

23. Simões, S.S.; Ajenjo, A.C.; Dias, M.J. Dried blood spots combined to an UPLC-MS/MS method for the simultaneous determination of drugs of abuse in forensic toxicology. J. Pharm. Biomed. Anal. 2018, 147, 634-644. [CrossRef] [PubMed] 
24. Moretti, M.; Freni, F.; Valentini, B.; Vignali, C.; Groppi, A.; Visonà, S.D.; Osculati, A.M.M.; Morini, L. Determination of antidepressants and antipsychotics in dried blood spots (DBSs) collected from post-mortem samples and evaluation of the stability over a three-month period. Molecules 2019, 24, 3636. [CrossRef] [PubMed]

25. Majda, A.; Wietecha-Posłuszny, R.; Świądro, M.; Mrochem, K.; Kościelniak, P. Dried blood spots sampling in case samples deprived of hematocrit level information-Investigation and calculation strategy. J. Chromatogr. B Anal. Technol. Biomed. Life Sci. 2019, 1124, 308-312. [CrossRef]

26. Wietecha-Posłuszny, R.; Lendor, S.; Garnysz, M.; Zawadzki, M.; Kościelniak, P. Human bone marrow as a tissue in post-mortem identification and determination of psychoactive Substances-Screening methodology. J. Chromatogr. B Anal. Technol. Biomed. Life Sci. 2017, 1061-1062, 459-467. [CrossRef] [PubMed]

27. Database for Drug and Drug Target Info 2021. Available online: https://go.drugbank.com/ (accessed on 20 November 2021).

28. Group, S.W.; Toxicology, F.; Methods, V.; Development, M.; Plan, V.; Validation, R.; Based, P.; Requirements, S.; Method, C.; Experiments, V.; et al. Scientific working group for forensic toxicology (SWGTOX) standard practices for method validation in forensic toxicology. J. Anal. Toxicol. 2013, 37, 452-474. [CrossRef]

29. Capiau, S.; Veenhof, H.; Koster, R.A.; Bergqvist, Y.; Boettcher, M.; Halmingh, O.; Keevil, B.G.; Koch, B.C.P.; Linden, R.; Pistos, C.; et al. Official International Association for Therapeutic Drug Monitoring and Clinical Toxicology Guideline: Development and Validation of Dried Blood Spot-Based Methods for Therapeutic Drug Monitoring. Ther. Drug Monit. 2019, 41, 409-430. [CrossRef] [PubMed] 